\title{
Landscape Archaeology and Artificial Intelligence: the Neural Hypersurface of the Mesopotamian Urban Revolution
}

\author{
Marco Ramazzotti \\ In collaboration with Paolo Massimo Buscema and Giulia Massini*
}

What people call "meanings" do not usually correspond to particular and definite structures, but to connections among and across fragments of the great interlocking networks of connections and constraints among our agencies.

MARVIN MINSKY, 1986, 131.

\section{Introduction}

Since the 1990s, there has been an unceasing debate over computer semiotics as an autonomous discipline aimed at establishing the function of the logical operators of programming and computing. ${ }^{1}$ In fact, the structural and semantic encoding of the analytical object also comprise one of the main trends in Natural Computing (NC) and in the fast-moving field of computer science. ${ }^{2}$

* From the Semeion Research Center of Rome.

1 Computer semiotics: any empirical approach mainly interested in the ways that humans and machines may communicate with each other using written languages, texts, and/or codes (Andersen 1991a, 3-30; 1991b, 1-32; Figge 1991, 321-330).

2 Natural Computing (NC): a nonlinear dynamics and pattern formation computing inspired by concepts, principles, and mechanisms underlying natural systems (Anderson and Rosenfeld 1988; McClelland and Rumelhart 1988). NC algorithms are inspired by natural and biological phenomena and include evolutionary algorithms, neural networks, molecular computing, and quantum computing (Brabazon, O' Neill, and McGarraghy 2015, 221-280). Computer Science brings together disciplines including Mathematics, Engineering, the Natural Sciences, Psychology, and Linguistics (Beckerman 1997; Miller and Pages 2007).

(C) MARCO RAMAZZOTTI, 2018 | DOI 10.1163/9789004375086_004

This is an open access chapter distributed under the terms of the prevailing CC-BY-NC License. 
Moreover, the possible encoding of the historical, archeological, anthropological, aesthetic, and linguistic records and contexts as a minimum unit of meaning (sema) defined a new epistemic perspective in ancient world studies. ${ }^{3}$ This new epistemic perspective, which currently also can be considered a recent branch of the digital humanities, is interested in translating the complex systems of the past into systems of signs and in turning each sign into a point (site) and node (or cell) composing many artificial formal networks. ${ }^{4}$

The present contribution introduces the theoretical and experimental approaches in encoding the complexity of the Mesopotamian Urban Revolution as an artificial network and in simulating the multifactorial relationships of this network with the biological computing of the Artificial Adaptive Systems $(\mathrm{AAS}) .^{5}$

\section{Methodology: Encoding, Translating, and Modeling}

The artificial formal network of a complex system can be considered a synthetic and formalized representation of observed reality. It is both an abstract model and an algebraic generalization of the reality that can be explored and simulated using statistical, mathematical, and physical models. ${ }^{6}$ Exploring and simulating both abstract models and algebraic generalizations of complex configurations, the mathematical and physical models of NC equal tracking down, selecting, and (separately) recreating: 1) a wide variety of functions associating variables, 2) a wide variety of inferences controlling their conceptual structure, and 3) an equally wide variety of rules producing their transformations. ${ }^{7}$

3 A new epistemic perspective recently advanced in theoretical (Ramazzotti 2010), historical (Ramazzotti 2013d), and empirical (Ramazzotti 2014a, 15-52) approaches to the study of the past.

4 For network analysis in Archaeology, see Bentley and Shennan (2003, 459-485), Brughmans (2010, 277-303), Barthélemy (2011, 1-101), Knappet (2011), Kohler (2012, 93-123), Ramazzotti (2013b, 283-303), Leeuw (2013, 335-349), and Collar et al. (2015, 1-32).

5 Artificial Adaptive Systems (AAS) are biological computing methods, techniques, and algorithms forming part of the vast world of Natural Computation/Natural Computing, which is itself a subset of the Artificial Sciences (AS). AS are those sciences for which an understanding of natural and/or cultural processes is achieved by the recreation of those processes through automatic models (Buscema 2014, 53-84).

6 Ramazzotti 2014a, 15-42.

7 For a general introduction and overview of $\mathrm{NC}$ - both of abstract models and of algebraic generalizations of archaeological, anthropological, and visual complex configurations-see 
Since the end of the 1980s, a matrix encoding of the Mesopotamian Urban Revolution has been in the process of development for the purpose of tracking down, ${ }^{8}$ selecting, and recreating the functions, inferences, and rules that produced the political, cultural, and economic transformations of the most ancient Urban Revolution.

The artificial formal networks obtained by such structural and semantic matrix encoding were thus massively described, analyzed, and simulated through the quantitative, qualitative, and symbolic methods of Artificial Intelligence (AI). ${ }^{9}$ After some 30 years of such theoretical and experimental research on the origin of the city-state and urbanism in the ancient Near East, the simulations of the Mesopotamian Urban Revolution Landscape (MURL) ${ }^{10}$ through the AI symbolic paradigm seem to maintain a distinct value. This distinct value is most evident in archaeological thought, where the MURL simulations serve both as a new analytical paradigm for computational modeling in Archaeology and as a new theoretical approach for the study of urbanism and urbanization. ${ }^{11}$

Ramazzotti (1997, 495-522), Reeler (1999, 3-10), Zubrow (2003), Bintliff (2005), Barceló (2008, 154-184), and Ludovico and Ramazzotti (2008, 263-280); Ramazzotti (2014a, 15-52). On matrix encoding and combinatorial analysis in Archaeology, see Kendall (1971, 215252) and Shuchat (1984, 3-14).

9 For the so-called symbolic paradigm, AI has been conceived as the development of models using symbol manipulation. The computation in the models is based on explicit representations that contain symbols organized in some specific structures. The connectionist paradigm aims at massively parallel models that consist of a large number of simple and uniform processing elements interconnected with extensive links, the Artificial Neural Networks (Smolensky 1987, 95-109).

We use the acronym "MURL" to identify the historical period and the economic concept of the Urban Revolution as they were delineated first by Vere Gordon Childe (1950, 3-17), as well as the area of the world's first urbanism - central-southern Iraq. On the geographical, archeological, and historical features of the MURL, see Ramazzotti (2002, 651-752).

11 One of the most significant turning points in the history of computational modelling in Archaeology is strictly related to the theoretical and empirical work of David Leonard Clarke on the System Theory paradigms and principles (Clarke 1968; 1972; 1977). This turning point cannot be summarized here, but for a recent critical historiography of computational modelling in Archaeology, see Ramazzotti (2013c, 23-56) and Ramazzotti (2014a, 15-52). Indeed, the most recent empirical theories on urbanism and urbanization are mainly based on settlement multifactorial complexity modelling through system theory and/or social theory (Smith 2011, 167-192); an "ecological approach," we could say, started with many works of systematic research on Mesopotamian urban civilization at the end of 1970s (Redman 1978a; 1978b, 329-347). For a recent historiography of Babylonian urbanism, urbanization, and city-state ideal-types, and for the role played also by the neu- 
The application of AAS to the MURL can elaborate new analytical hypersurfaces that can exhibit nuances and complex interrelations and, furthermore, can help the researcher to discover other, unforeseen (or even hidden) interrelationships. ${ }^{12}$

\section{The Neural Modeling of the MURL}

One of the first applications of AAS to the MURL (encoded in different matrixes) was advanced and tested at the Semeion Research Center (Rome) and at La Sapienza University of Rome and published in $1999 \cdot{ }^{13}$

At that time, the main problem was how to properly encode and simulate the systemic settlement complexity of the most ancient urbanism, integrating data from excavated sites, surface surveys, and a mixture of each, in order to reveal and analyze the cultural, political, and economic interrelationships of the Mesopotamian Urban Revolution. ${ }^{14}$ In this respect, the land of Sumer's settlement system was first encoded in a matrix composed of records (208 archaeological sites) and variables (95 geographical, morphological, and cultural

ral approach to the systemic complexity of the Mesopotamian settlement systems, see Liverani (2013).

AAS are AI deep-learning models and algorithms that simulate physical or cultural phenomena and features that have been previously encoded, so that from processing such models previously unknown relationships can be revealed through the features. The application of such types of models and algorithms to the MURL natural and cultural phenomena encoded in matrixes can be considered a new combinatory analysis of an artificial formal network, and the NC of the MURL can recreate a possible world of other associations of meaning from the body of incomplete sources and scattered information (Ramazzotti 1997, 495-522; 1999; 2000, 9-38; 2002, 651-752; 2003, 15-71; 2009, 193-202; 2013a, 10-34; 2013b, 283-303; 2013c, 23-56; 2014a, 15-52; 2014b, 53-84; 2016a, 17-26; 2016b, 183-194).

13 Ramazzotti 1999. These were the first applications of biological computing to the MURL (encoded in different $n$-dimensional matrixes); they were tested at the Semeion Research Center and discussed in the Department of Historical, Archaeological, and Anthropological Sciences of Antiquity at La Sapienza University in 1996.

This data mainly resulted from the pioneering field, satellite, spatial, and analytical surveys directed by Robert McCormick Adams, Henry T. Wright, and Hans J. Nissen in central-southern Iraq (Adams 1955, 6-18; 1956, 227-232; 1972a, 735-749; 1972b, 6o-62; 1978, 329-335; 1981; 2008, 1-23, <http://cdli.ucla.edu/pubs/cdlj/2008/cdlj2008_001.html> [accessed June 9, 2017]; Nissen 1980, 285-29o; 1983a, 91-106; 1983b, 287-294; 2001, 149-179; Adams and Nissen 1972; Wright 1977, 379-397; 1978, 49-68; 1981, 297-362; 1984, 41-78; 1986, 141-155; 1998, 173-192; 2001, 123-148). 
variables). ${ }^{15}$ Then the matrix was analyzed by simulating any possible relationships between archaeological sites and variables through different types of Artificial Neural Networks (ANNs). ${ }^{16}$ This neural modeling of the MURL empirically approached many cultural, settlement, and economic arguments of the world's first urbanism, revealing many connections from the body of incomplete sources and exhibiting the nuances and complex interrelations.

The specific use of ANNs as a classification method improved for Southern Mesopotamian protohistoric pottery technically confuted the existence of a Middle Uruk sub-typology in Sumer. ${ }^{17}$

The specific use of ANNs as a spatial analysis method on the central-southern Mesopotamian settlement distribution specifically focused on the peculiar

15 The analysis was founded on the archeological material from the Uruk, Akkad, Kiš, and Nippur surveys (Ramazzotti 1999, 259-269). The 95 parameters describing each archaeological deposit were mostly sub-articulated in six macro-groups: a) settlement and site morphology, b) environmental and adaptive context, c) architectural and visible remains, d) cultural and technological milieu, e) pottery typologies, and e) occupation phases. The occupational sequence of each settlement from the second half of the fifth to the second half of the third millennium BCE was subdivided according to the classical periodization of ancient Mesopotamia (Porada et al. 1992, 77-121) into the main seven periods of the southern Urban Revolution process (Ubaid IV: UBIV; Early Uruk: EU; Middle Uruk: MU; Late Uruk: LU; Jemdet Nasr: JN; Early Dynastic I: EDI: Early Dynastic II - III: EDII - III), and the most conspicuous occupation phases were selected for each site based on both the quantities and qualities of the dating materials.

Artificial Neural Networks (ANNs): learning systems; these are algorithms for processing information that allow for the reconstruction, in a particularly effective way, of the approximate rules relating to a set of "explanatory" data concerning the considered problem (the input), with a set of data (the output) for which it is requested to make a correct forecast or reproduction in conditions of incomplete information (Buscema 2014, 53-84). See also in this volume, applied a) to art, Ludovico, 92-94 and b) to semantics, Svärd, Jauhiainen, Sahala, and Lindén, 228-229, 246-249.

17 The typological subdivision of archaeological pottery also can be considered a Constraint Satisfaction (Cs) problem, in which the recognition of a class or a type must satisfy a number of constraints. Most of the conventional approaches to solving cs problems improved the algorithms by processing the constraints. The ANNs' approach was completely different, since, in a Neural Network, the constraints are encoded in a net topology (biases and connections), and when a network sets in a stable configuration, the pattern of firing neurons represents the solution. See Mézard and Mora (2009, 107-113). In particular, applying the ANNs classification method, the existence of the Middle Uruk pottery sub-typology was refuted. This absence revealed the functional role played by this latent horizon in the explanation of the southern Urban Revolution as an orthogenetic process, inspired by market-oriented economic categories (Ramazzotti 1997, 495-522). 
relationship between settlement morphology and spatial organization in the hinterland of the site of Uruk (Warka). ${ }^{18}$

Since the end of the 199os, moreover, the neural modeling approach has also analytically challenged the most ambitious demographic hypothesis on the origin of the Mesopotamian city-state. ${ }^{19}$

Indeed, to explore the possible relationships between the high spatial variability of southern Mesopotamian settlement organization and human mobility, unsupervised networks were tested to draw inferences between settlement morphologies, ${ }^{20}$ settlement distributions, and settlement dynamics. ${ }^{21}$

18 For a specific discussion on the recognition of the Jemdet Nasr period (c. 3100-2900 BCE) as either a distinct archeological period of the Mesopotamian Urban Revolution or as a regional pottery style, see Finkbeiner $(1986,33-56)$ and Ramazzotti $(2000,9-38)$. In this case, the neural-spatial analysis showed the Jemdet Nasr settlement pattern not as a phase of collapse rendering a hard break in culture at the end of the Urban Revolution, but rather as a different and peculiar regional adaptation to manage central-southern Mesopotamian hydrological resources (Ramazzotti 2002, 651-752).

19 Adams 1972a; 1972b; Young 1972, 827-842; Gibson 1973, 447-463; Weiss 1977, 347-369; Brinkman 1984, 169-180.

20 In this case the Kohonen's features maps/Self-Organizing Maps (soms) have been used. The som is a type of learning algorithm used to draw inferences from datasets and to order high-dimensional statistical data so that neighboring nodes on the map represent similar inputs. Often the som is applied to numerical data in application areas such as pattern recognition, signal processing, and multivariate statistical analysis (Kohonen $1982,59-69)$. In other words, the som is an unsupervised type of network that offers a classification of the input vectors, creating a prototype of the classes and a projection of the prototypes on a map having two dimensions (but $n$-dimensional maps are also possible) that is able to record the relative proximity (or neighborhood) between the classes (Kohonen 1996, 281-291; Massini 2010, 313-348). Regarding multivariate analysis, see in this volume, Martino and Martino (118-119), who discuss the method, in particular, for making object-typologies.

21 Since the key advantage of the som is the clustering, which reduces the input space into representative features of a map, comparing different output maps' strong correlations between the morphology of the archaeological sites, assessments of the hydraulic landscape and anthropic mobility trends were observed. During the Late Uruk period (c. 3500-3100 BCE), the local southern population was predominantly settled in stable anthropic deposits close to the canals, but during the subsequent, Jemdet Nasr period (c. 3100-2900 BCE), the population settled in more dispersed patterns, that fit what Adams and Nissen (1972, 24, fig. 11) describe as composite and multiple occupations. Then settlement adaptation patterns drastically changed during the subsequent Early Dynastic period (c. 2900-2350 ВСE), when, on account of a process of small-settlement aggregation (synoecism), the dispersed population probably shifted northernmost and converged onto more isolated sites in the region of Nippur (Ramazzotti 2003, 15-71; 2009, 193-202). 


\section{The Biological Modeling of the MURL}

A turning point in the neural modeling of the MURL was the investigation of an empirical analogy between the complexity of the archaeological settlement systems and the complexity of the biological system. ${ }^{22}$ Considering the spatial relations between points (sites) as the nodes and/or cells of a highly interconnected net, we translated the spatial-temporal segments (sites) of the MURL into a network, intended as a membrane dynamically activated by different actions, causes, and/or events. ${ }^{23}$

Each point of the membrane was thus conceived as a geo-referenced archaeological site, and the adaptive network was trained first through the most advanced generation of AAs. Then, the highly sophisticated outputs of the training were optimized, formalized, and displayed through data-mining algorithms in tree-graphs. ${ }^{24}$ The graph analysis of the deep learning of the membrane/network was thus tested as a predictive spatial tool for locating the possible position of undiscovered monuments and/or sites. ${ }^{25}$

In particular, graph-algorithms were applied on a matrix generated by the last ANNs generation to predict the possible spatial localization of the Ebla Royal Mausoleums in the hinterland of Tell Mardih-Ebla, in northern Syria. ${ }^{26}$

Moreover, the same integrated method (ANNs training and graph analysis) has been applied to identify correlations between settlement distributions and cultural, technological, and economic variables between the Ubaid (c. 65003800 BCE) and Uruk periods (c. $3800-3100$ BCE) in south-central Babylonia. ${ }^{27}$

22 For this assumption, see Ramazzotti $\left(2014 \mathrm{a}, 15^{-52}\right)$.

23 Ramazzotti 2013b, 283-303; 2013c, 23-56.

24 "For the purposes of archaeological analysis, graph theory can be defined as a mathematical method to describe the kind, direction and magnitude of interconnections between individuals or groups at differing nodes of activity and to analyze the underlying systematic structure that the whole set of interconnections implies" (Rothman 1987, 73).

A computerized learning machine takes precise input and produces definite output as "true" or "false," which is equivalent to a human's "yes" or "no." Artificial neural learning of complex configurations can be understood to emulate human learning based on fuzzy logic, as it operates on degrees of possibilities of input to achieve definite output.

26 Regarding the last ANNs generation, see also footnotes 30 and 36 . Auto-CMs (which stands for Auto-Contractive Maps) 'spatialize' the correlation among variables by constructing a suitable embedding space where a visually transparent and cognitively natural notion, such as 'closeness' among variables, reflects accurately their associations" (Buscema et al. 2009, 8; Ramazzotti 2013a, 10-34).

In particular, the A-Temporal Diffusion Model (ATDM) equation and Auto-CM Artificial Neural Network has been recently sketched, tested, and presented as a learning machine method for the training of a large matrix composed by 496 archaeological sites (records) 
The hypersurface outputs of neural learning have been explored by integrating the traditional Minimum Spanning Tree (MST) graph analysis with the Maximally Regular Graph (MRG) new algorithms. ${ }^{28}$ This integrated approach was thus adopted to recognize the logic of the spatial distribution of two of the most significant cultural-material records in the region: the Ubaid clay sickles and the Uruk clay cones (Fig. 2.1a-b). ${ }^{29}$

The uniformly distributed presence of clay sickles and clay cones in the MST-MRG tree-graph, and the distribution of the branches of the tree-graph,

described by 106 parameters (variables). ATDM is a recently proposed algorithm that has been developed to detect the dependencies among pairs of variables in a large dataset, while also taking approximate account of their higher-order relationships with other variables (Buscema et al. 2013b, 231-275).

28 From a conceptual point of view, the MST represents the energy-minimization state of a structure. In fact, if we consider the atomic elements of a structure as the vertices of a graph and the strength among them as the weight of each edge linking a pair of vertices, the MST represents the minimum of energy needed so that all the elements of the structure preserve their mutual coherence. In a closed system, all the components tend to minimize the overall energy. So the MST, in specific situations, can represent the most probable state for the system. For the classical formulation of the MST (Kruskal 1956, 48-50), see Buscema and Sacco (2016, 726-746). Despite other seriation techniques, the MST data-mining method permits branching structures that also reveal clustering in archaeological datasets (Hage, Harary, and Brent 1996, 149-155); this method has been applied as a model for spatial analysis in different ways. The MRG algorithm can be considered a new type of semantic graph that uses a new index for detecting structural/topological complexity information in undirected graphs (H function). In fact, from an MST, generated from any metric, the MRG reshapes the links among nodes in order to maximize the fundamental and most regular structures implicated in any dataset. The MRG algorithm generates, starting from the MST, the graph presenting the highest number of regular microstructures that make use of the dataset's most important connections. Compared to the MST, therefore, the MRG adds all (and only) those extra features that are really useful in understanding the prototypes that are hidden in the database; in other words, it adds the optimal amount of complexity that is necessary to read the phenomenon. In terms of our specific object of study, the MRG represents an alternative graph-theory representation of the underlying power network with respect to the one obtained by simply reconstructing the geography of common board affiliation (Buscema and Sacco 2010, 227-276; Buscema et al. 2016, 355-378).

29 The Ubaid clay sickles (fifth to fourth millennium BCE) are usually associated with the first intensive agricultural activities in the alluvial plain (Benco 1992, 119-134; Stein 2010, 23-44), and the Uruk clay cones (fourth millennium BCE) are linked to the ideographical and symbolical representations of the most important religious buildings of the first southern Mesopotamian cities (Brandes 1971; Wright and Johnson 1975, 267-289; Cooper 1985, 97-114). 


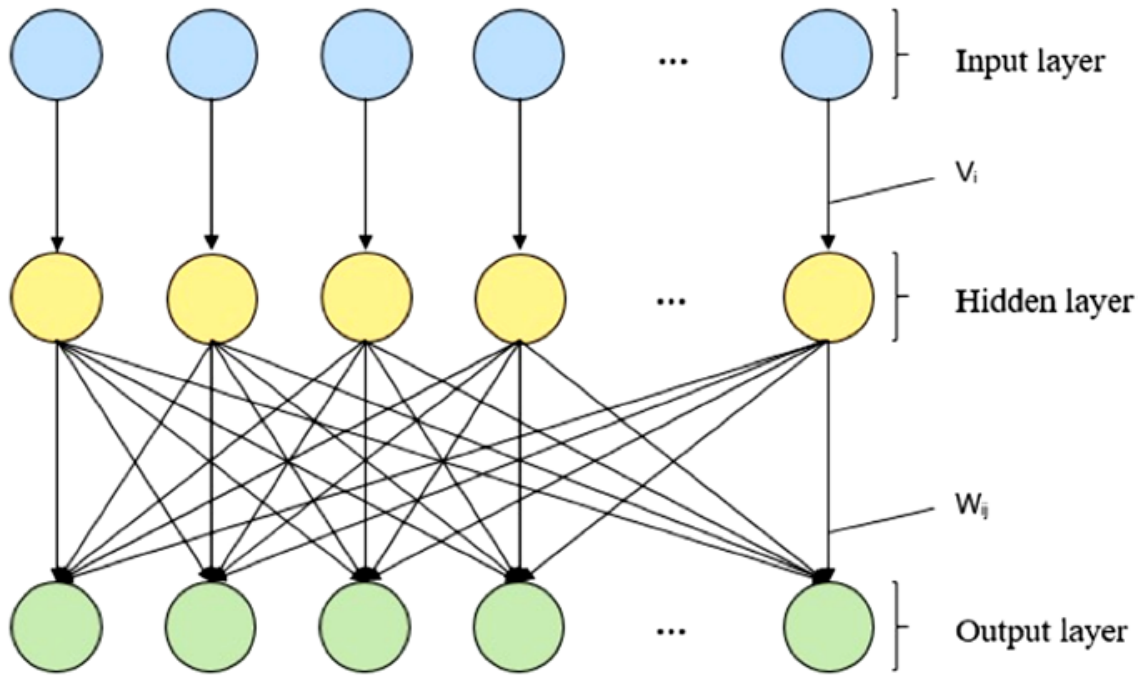

FIgURE 2.1a Auto-CMANN (BY PAOLO M. BUSCEMA (C) SEMEION)

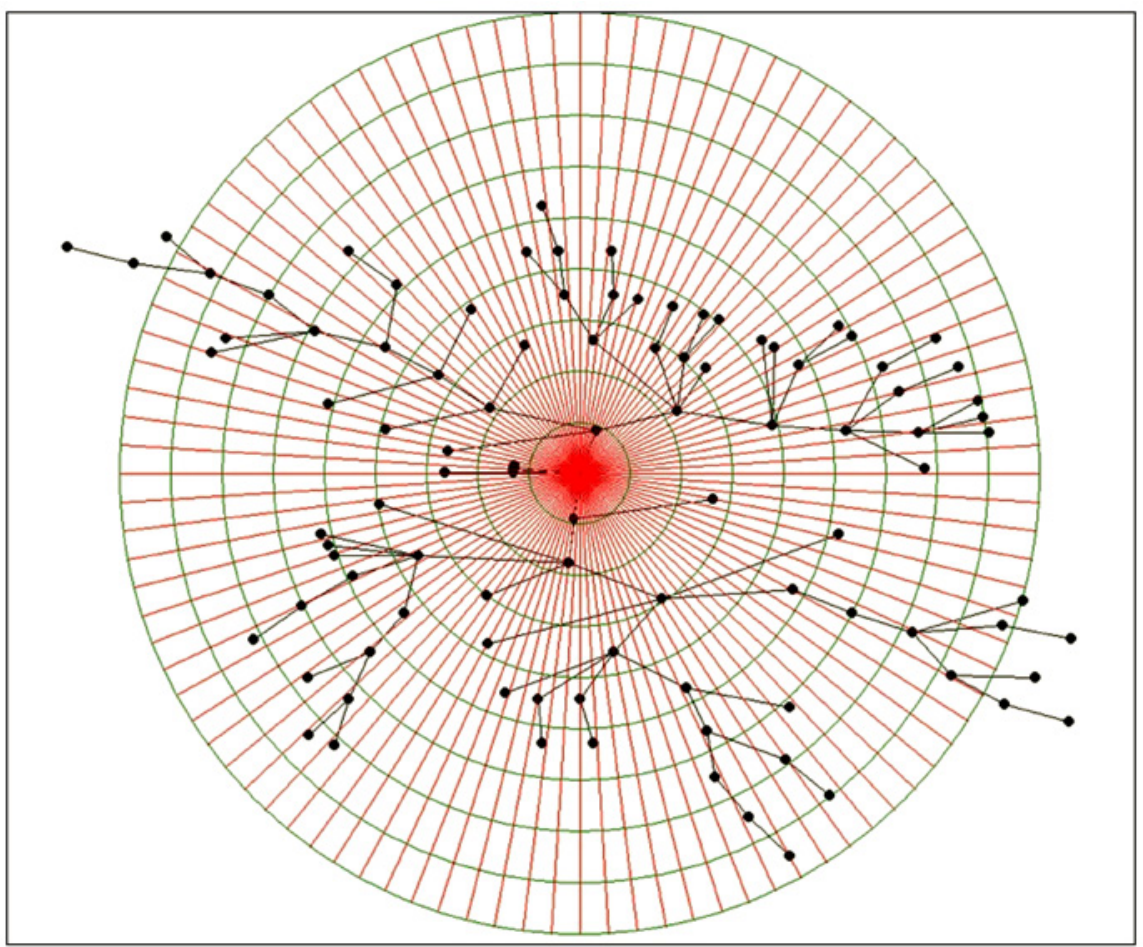

FIGURE 2.1b Tree-Visualizer(BY GIULIA MASSINI C SEMEION) 


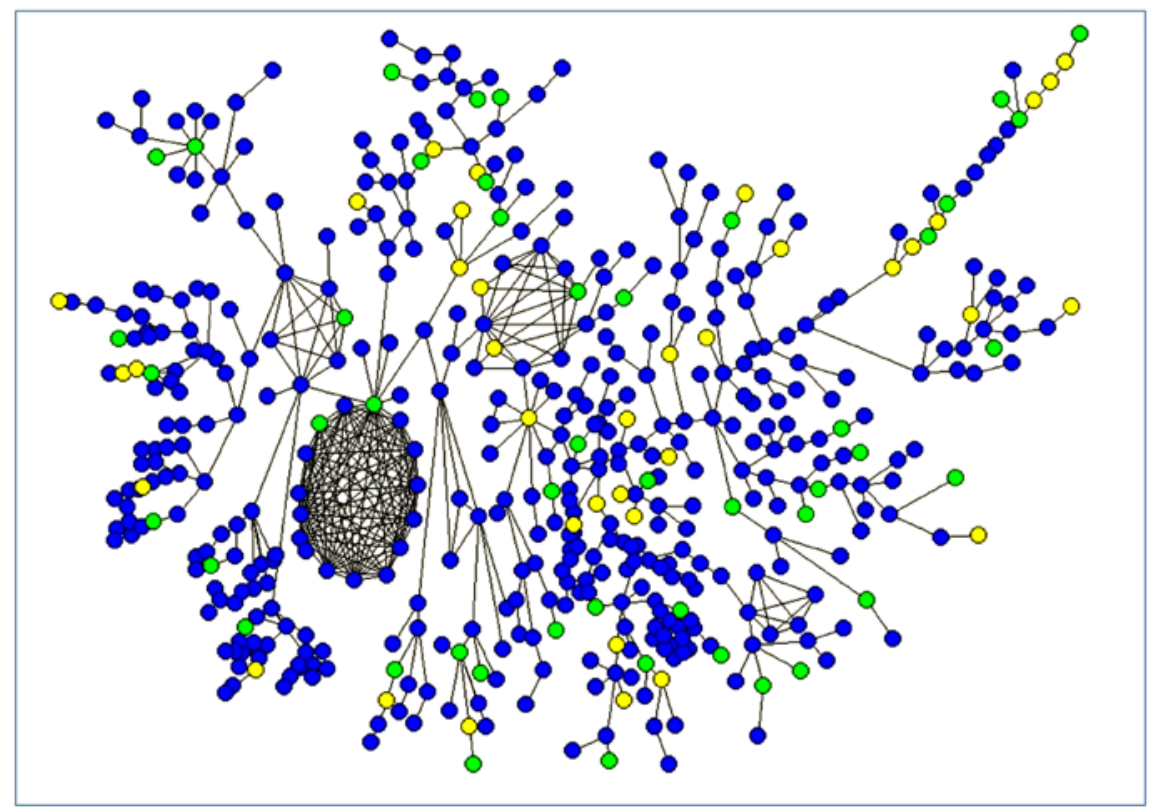

FIGURE 2.2a Auto-CM-MST-MRG graph. The presence of the clay sickles (green points) and clay cones (yellow points) is uniformly distributed on the MST-MRG tree-graph. The distribution on the tree branches could indicate a homogenous spatial relationship between food-production activities and symbolic/religious functions.

could indicate a homogenous spatial relationship between food production activities and symbolic and/or religious functions (Fig. 2.2a).

On the contrary, by testing the same neural training outputs on the distribution of the two variables together (clay sickles and the clay cones) we observed a sensible reduction in the number of occurrences (Fig. 2.2b).

The co-existence of the two variables in specific regions of the graph-tree could thus implicate a possible nuclear settlement organization and could suggest a pilot role, on both economic and symbolic levels, played by some specific sites across the whole settled area between the end of the fifth millennium BCE and the end of the fourth millennium BCE.

\section{The Topological Modeling of the MURL}

Recently, research on the MURL has been advanced by the exploration, through a new data-mining experimental procedure (see Appendix 2.1), of the spatial semantics of the settlement distributions in the region between Ur 


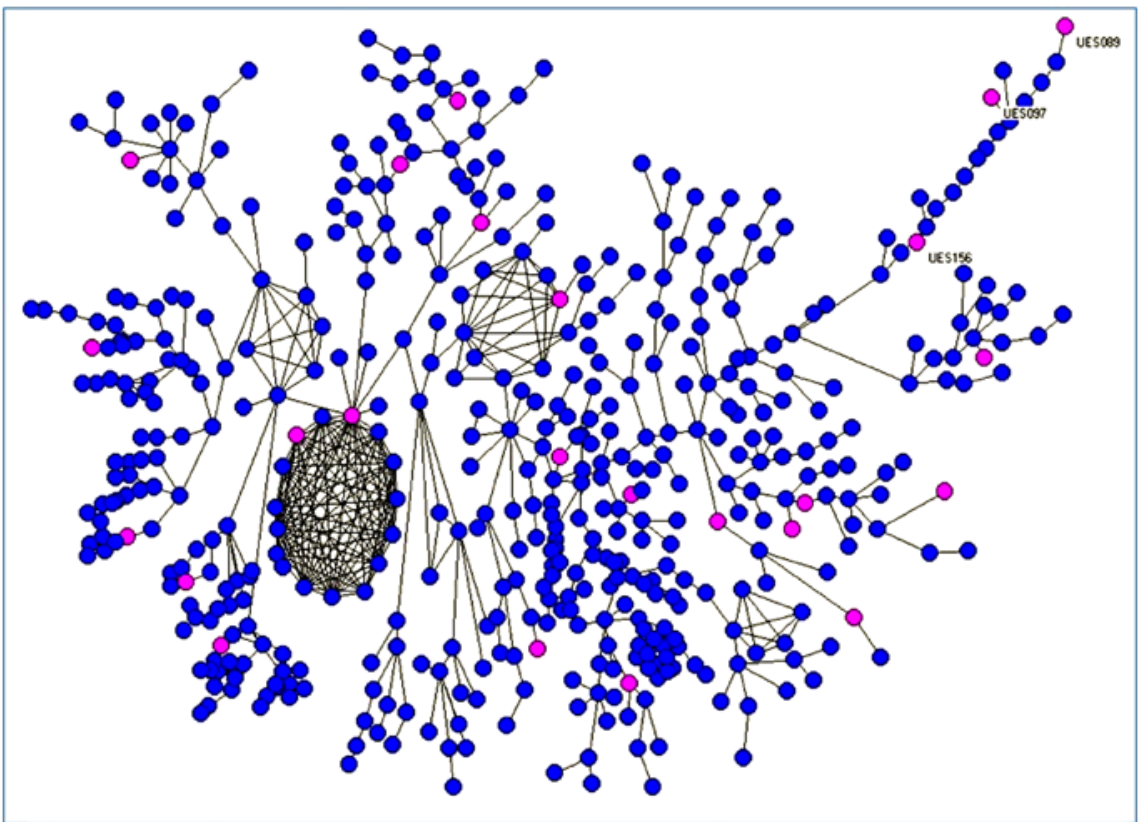

FIGURE 2.2 b Auto-CM-MST-MRG graph. Testing the same neural hypersurface on the distribution of the two variables together (clay sickles and the clay cones), we observed a sensible reduction of the number of occurrences (purple points). The coexistence of the two variables in specific regions of the graph-tree could thus implicate a possible nuclear organization.

(Tell Muqayyar) and Uruk (Warka). In particular, the spatial semantic of the MST-MRG graph-trees resulting from the neural learning of the Ur and Uruk settlement network through the new algorithm of the Topological Weighted Centroid (TWC) has been discussed (see Appendix 2.2). ${ }^{30}$

The aims of this applied research are to focus on the possible topology of the MURL and to investigate the topography of movement of these shapes and forms through time. ${ }^{31}$ Following this new space-analysis to the geographical profiling, we first have selected the fifth, fourth, and third millennium BCE settlements of the region between Ur and Uruk.

30 For a detailed explanation of the TwC, see Appendix 2.2 by Paolo Massimo Buscema. The TWC mathematical approach explores the natural and anthropic landscape with respect to certain quantities (entropy), spatializing the optimal solutions in the centers of the masses (Buscema, Breda, and Catzola 2009; Buscema, Grossi, and Jefferson 2009; Buscema 2014; Buscema et al. 2015, 532-567).

$31 \quad$ To approach movement from a computational perspective by creating tools that can help to cope with its fluid and emergent nature, see Mlekuž $(2014,5)$. 
Second, we tested the TWC algorithm on the Auto-CM and the ATDM neural hypersurfaces of a new dataset (224 sites for 106 variables). Lastly, we generated four TWC maps for each individual period of the Urban Revolution process (the Ubaid, c. 6500-380o BCE; the Uruk, c. 3800-3100 BCE; the Jemdet Nasr, c. 3100-2900 BCE; and the Early Dynastic, c. 2900-2350 BCE), superimposing the results on a satellite photo of the region between Ur and Uruk.

Since we define the TwC map of $n$-entities in a two-dimensional space as the center of mass of these entities, weighted by the proximity of each entity to the others, ${ }^{32}$ we have produced TwC distribution maps for each chronological sequence of the MURL (period 1, period 2, period 3 , and period 4).

The four maps selected here describe a diachronic trajectory (periods 1, 2, 3, 4) across the same space (the region between Ur and Uruk) and thus display a semantic topology of the most significant geographical, morphological, and cultural features of the MURL (Fig. 2.3).

At the present state of our research, this diachronic trajectory can only be intended as the spatial-temporal diffusion of a centroid, where the centroid here simulated is the center of mass of the variables (106 geographical, morphological, and cultural variables) defining each individual archaeological site in the region (224 sites).

The diachronic changes of these centers of mass on the four maps seem to demonstrate an ancient spatial history of the Mesopotamian Urban Revolution akin to a mitosis process, a biological process of cell duplication, or reproduction. ${ }^{33}$

Turning back to the future, ${ }^{34}$ the morphogenesis of this topology opens another fascinating frontier for the analysis of the world's first urbanism: the topological modeling of the settlement networks intended as adaptive and dynamic biological membranes.

32 According to the TwC mathematical paradigm, if we take the center of mass of the distribution as the natural reference, we can therefore consider how the distance between the center of mass and any given point is influenced by the relative distance of all other points in the distribution (Buscema et al. 2013a, 75-139).

In fact, the first TwC map related to the Ubaid period shows two separated centroids, in the southern and northern parts of the selected area; the second and the third TwC maps related to the central periods of the Urban Revolution display only one centroid (in the northern sector of the selected area), and the fourth map repeats the same two-centroid distribution of the first map. 
PERIOD 1 (5000-4000 BCE ca.)

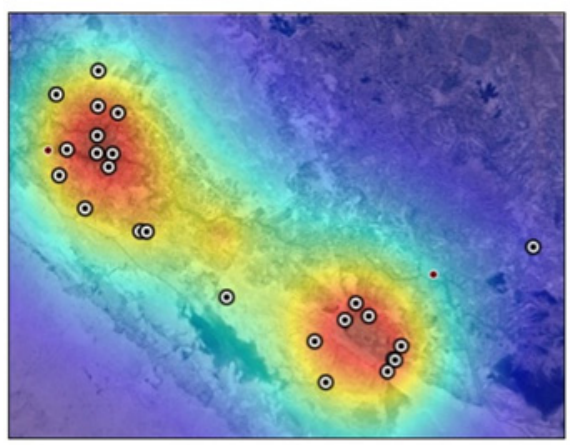

PERIOD 3 (3100-2900 BCE ca.)

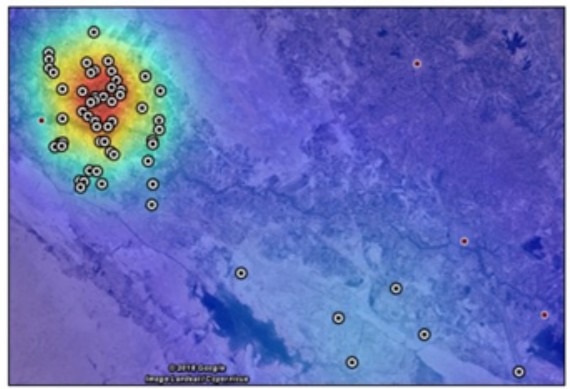

PERIOD 2 (4000-3100 BCE ca.)

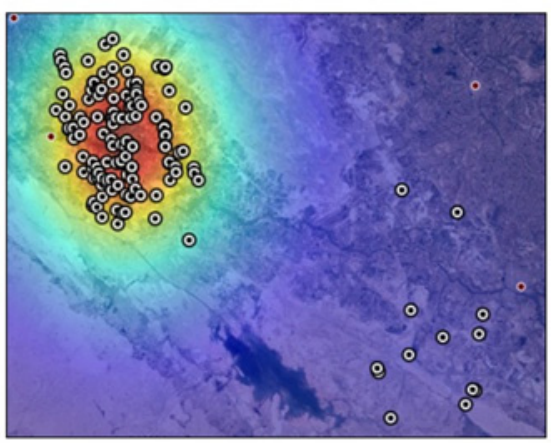

PERIOD 4 (2900-2350 BCE ca.)

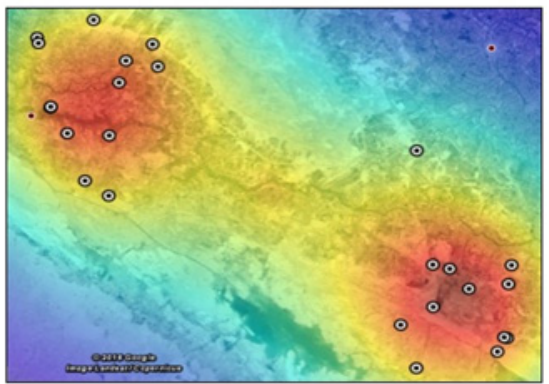

FIGURE 2.3a-d The four period TwC Gamma $(\gamma)$ maps of the MURL. Each map describes the extent to which each point of the space is activated by its closeness to any of the points belonging to any of the nonlinear trajectories connecting each point to the center of mass.

\section{Appendix 2.1. The Experimental and Simulation Procedures ${ }^{35}$}

A complex machine-learning system (Fig. 2.4) has been adopted to process the MURL encoded data and transpose it in an $n$-dimensional matrix (224 sites for 106 geographical, morphological, and cultural variables).

The experimental process has been subdivided into four steps:

1. The archaeological records divided into the four main periods (Ubaid, Uruk, Jemdet Nasr, and Early Dynastic) of the Urban Revolution were first formalized in an $n$-dimensional matrix in which each site has been described by geographical, morphological, and cultural variables. The $n$-dimensional matrix, thus formalized, has been transposed in a Boolean matrix to constitute the Input of the Auto-CM (Auto-Contractive Map) Artificial Neural Network. The Auto-CM can be

35 By Giulia Massini (Semeion Research Center). 


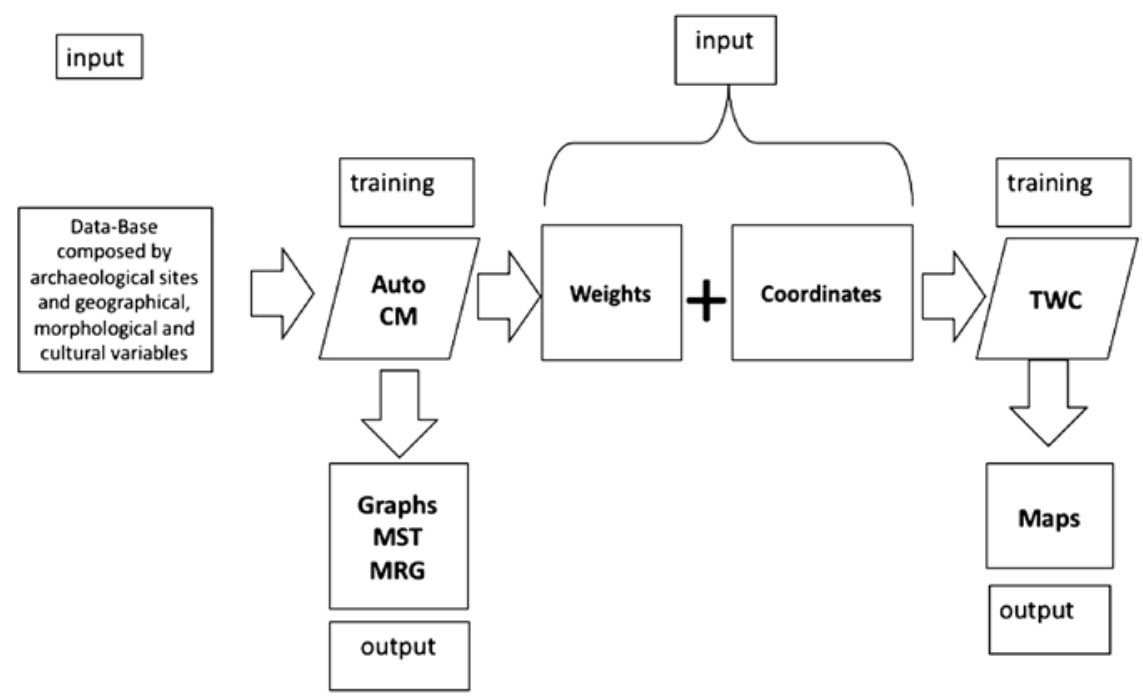

FIGURE 2.4 Machine-learning system for the neural simulation of the MURL

(C) SEMEION - GIULIA MASSINI)

viewed as a neural network with three layers of units, with each unit being connected to the next unit as shown in Fig. 2.1a. ${ }^{36}$

2. After the training phase, the weights developed by Auto-CM are proportional to the strength of the associations of all records to each other. The weights $W$ are then transformed into physical distances and saved on a symmetric matrix of relationships between records, with a null diagonal. The matrix of distances derived from the Auto-CM matrix of similarities has been explored through graph theory. A graph is a mathematical abstraction that basically consists of a set of vertices and a set of edges, where an edge represents the connection between two vertices on a graph.

3. A distance matrix among vertices $V$ represents an undirected graph, where each vertex relates to all the others except for itself. Consequently, each distance between a pair of nodes (archaeological sites) becomes the weighted edge between this pair of nodes. A simple mathematical filter represented by MST is applied to

36 The Auto-CM neural network was designed by Buscema in 1999 and is characterized by a three-layer architecture consisting of 1) an input layer, where the signal is captured from the environment; 2) a hidden layer, where the signal is modulated inside the Auto-сM; and 3) an output layer, through which the Auto-cm feeds back upon the environment on the basis of the stimuli previously received and processed. The top layer is the input layer, and these are equivalent to the variables among which we seek to identify relationships. 
the distances matrix, and a graph is generated, but to obtain major complexity in information, MRG was used.

4. The MRG describes other high-value relationships between records that are obtained from the Auto-CM analysis and are not shown by the MST. Such MRG relationships are represented as arcs creating circuits. Based on the values of the proximity relations between the archaeological settlements obtained by the Auto-CM, ANN has been connected to the value of the physical proximities. In other words, the values of proximity thus obtained has been linked to the spatial coordinates (latitude and longitude) to display the neural morphology of the settlement distributions (see TWC maps).

\section{Appendix 2.2. The Topological Weighted Centroid Basic Definitions $^{37}$}

The basic intuition behind the Topological Weighted Centroid (TWC) approach is that every distribution of a point in space has an implicit semantics, provided the following conditions are met: 1) each point of the distribution represents a discrete occurrence of the same process, 2) the distribution of points is statistically representative of the process to be analyzed, and 3) TWC is a set of ordered mathematical quantities that transforms the discrete dataset into different scalar fields: Alpha, Beta, Gamma, Theta, and Iota (Fig. 2.5).

The TwC Alpha $(\alpha)$ represents a spatial estimate of the hidden (outbreak) point, or area, where the process under study originated. The ideal candidate for an outbreak is a region that represents the portion of space from which the information needed to code and retrieve the relative position of all the other events is optimized - that is, the location from which the global entropy of the distances from all the other points attains its minimum level, and the correlated Free Energy is maximum. TwC Alpha represents the more rational past of the process.

The тwс $\operatorname{Beta}(\beta)$ is the spatial estimation of the relevance of the areas probabilistically linked to the process represented by the distribution of the points to be analyzed. The closer the points are to each other, the stronger the attraction they exert. The TwC Beta represents the actual state of the process.

The TwC Gamma $(\gamma)$ will describe the extent to which each point of the space is activated by its closeness to any of the points belonging to any of the nonlinear trajectories connecting each point to the center of the mass. The Gamma scalar field may therefore be thought of as a further qualification of the Beta field, which transforms attraction strengths into intensities of network interaction and therefore highlights

37 By Paolo Massimo Buscema (Semeion Research Center). 


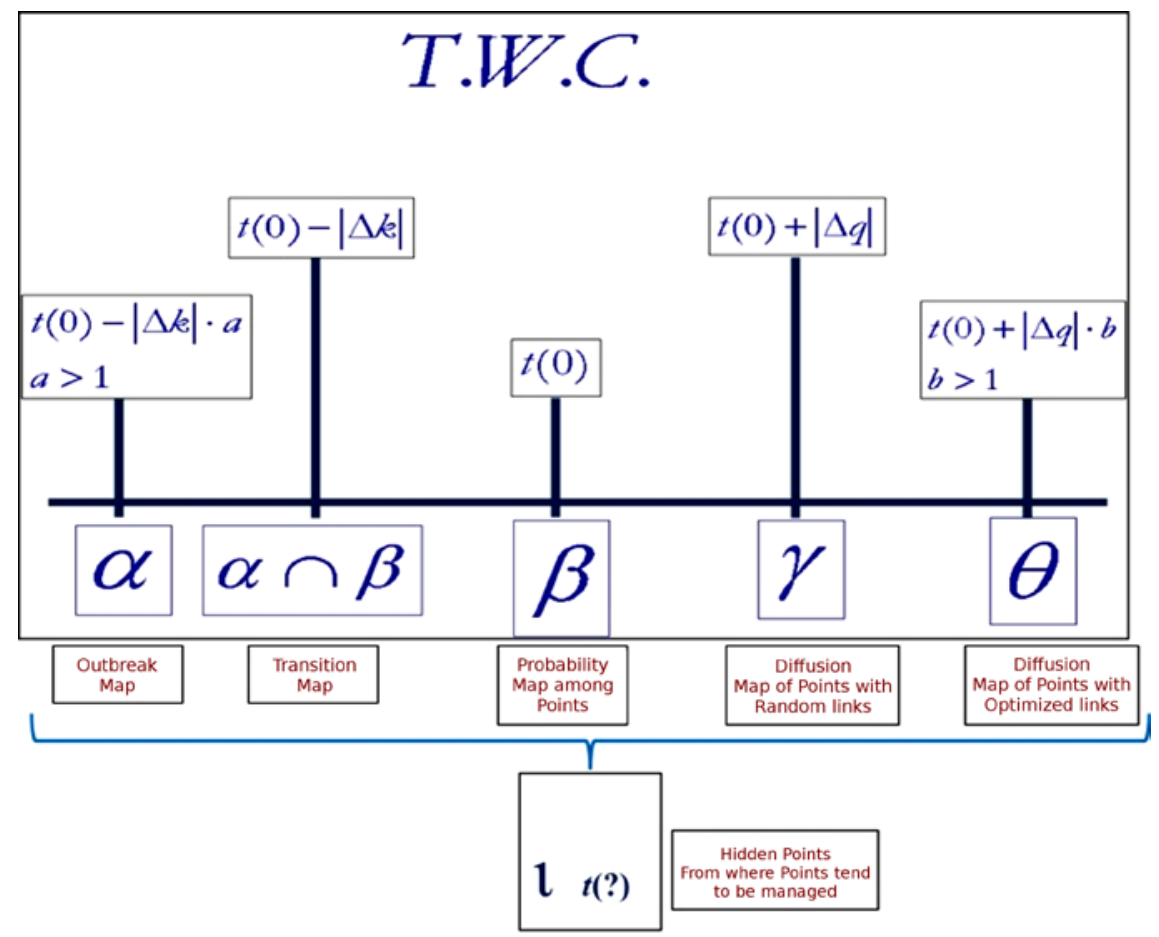

FIGURE 2.5 TWC algorithms (C SEMEION - PAOLO M. BUSCEMA)

longer-term activation patterns within the spatial distribution. The TwC Gamma represents the next evolution of the process.

The TWC Theta $(\theta)$ allows one to build the nonlinear MST that links together the points of $e$ spatial distribution in terms of a minimal network of influence. The nonlinear MST generated represents the ideal network of intercommunication among points if the contextual conditions remain stable. The TwC Theta represents the final evolution of the process.

The TwC Iota ( $($ ) allows one to estimate the vanishing points of the actual distribution of points. It indicates hidden areas where the assigned points could be clustered in an optimal way. From an empirical viewpoint, these areas may indicate the points from which the process is managed.

\section{References}

Adams, Robert McCormick. 1955. "Developmental Stages in Ancient Mesopotamia." In Irrigation Civilizations: A Comparative Study, edited by Julian H. Seward, 6-18. 
Washington, DC: Social Science Section, Department of Cultural Affairs, Pan American Union.

Adams, Robert McCormick. 1956. "Some Hypotheses on the Development of Early Civilization." AmAnt 21 (3): 227-232.

Adams, Robert McCormick. 1972a. "Pattern of Urbanization in Early Southern Mesopotamia". In Man, Settlement and Urbanism, edited by Peter J. Ucko, Ruth Tringham, and Geoffrey W. Dimbleby, 735-749. London: Duckworth.

Adams, Robert McCormick. 1972b. "The Urban Revolution in Lowland Mesopotamia." In Population Growth: Anthropological Implication, edited by Brian Spooner, 60-62. Cambridge, MA: MIT Press.

Adams, Robert McCormick. 1978. "Strategies of Maximization, Stability, and Resilience in Mesopotamian Society, Settlement and Agriculture." Proceedings of the American Philosophical Society 122: 329-335.

Adams, Robert McCormick. 1981. Heartland of Cities, Surveys of Ancient Settlement and Land Use on the Central Floodplain of the Euphrates. Chicago: The Oriental Institute of the University of Chicago.

Adams, Robert McCormick. 2008. "An Interdisciplinary Overview of a Mesopotamian City and its Hinterlands." Cuneiform Digital Library Journal 1. <http://cdli.ucla.edu/ pubs/cdlj/2008/cdlj2008_oo1.html>.

Adams, Robert McCormick, and Hans J. Nissen. 1972. The Uruk Countryside. The Natural Setting of Urban Societies. Chicago: The Oriental Institute of the University of Chicago. Andersen, Peter B. 1991a. "Computer Semiotics." SJIS 3: 3-30.

Andersen, Peter B. 1991b. A Theory of Computer Semiotics. Cambridge: Cambridge University Press.

Anderson, James A., and Edward Rosenfeld, eds. 1988. Neurocomputing Foundations of Research. Cambridge, MA: MIT Press.

Barceló, Juan A. 2008. Computational Intelligence in Archaeology. Investigations at the Interface between Theory, Technique and Technology in Anthropology, History and the GeoSciences. London: IGI Global.

Barthélemy, Marc. 2011. "Spatial Networks." Physics Reports 499: 1-101.

Beckerman, Martin. 1997. Adaptive Cooperative Systems. New York: Wiley-Interscience.

Benco, Nancy L. 1992. "Manufacture and Use of Clay Sickles from the Uruk Mound, Abu Salabikh." Paléorient 18: 119-134.

Bentley, R. Alexander, and Stephen J. Shennan. 2003. "Cultural Transmission and Stochastic Network Growth." AmAnt 68: 459-485.

Bintliff, John 2005. "Being in the (Past) World: Vermeer, Neural Networks and Archaeological Theory." In Die Dinge als Zeichen: Kulturelles Wissen und materielle Kultur, edited by Tobias L. Kienlin, 125-131. Bonn: Habelt. 
Brabazon, Anthony, Michael O'Neill, and Seán McGarraghy. 2015. Natural Computing Algorithms. Berlin - Heidelberg: Springer.

Brandes, Mark A. 1971. Untersuchungen zur Komposition der Stiftmosaiken an der Pfeilerhalle der Schicht Iva in Uruk-Warka. Baghdader Mitteilungen Beihefte 6. Berlin: Mann.

Brinkman, John A. 1984. "Settlement Surveys and Documentary Evidence: Regional Variation and Secular Trend in Mesopotamian Demography." JNES 43 (3): 169-180.

Brughmans, Tom. 2010. "Connecting the Dots. Towards Archaeological Network Analysis." OxfJA 29 (3): 277-303.

Buscema, Paolo M. 2014. "The General Philosophy of Artificial Adaptive Systems." In Archeosema. Artificial Adaptive Systems for the Analysis of Complex Phenomena. Collected Papers in Honour of David Leonard Clarke, edited by Marco Ramazzotti, 53-84. ACalc: Supplemento 6. Florence: All'Insegna del Giglio.

Buscema, Paolo M., Masoud Asadi-Zeydabadi, Weldon A. Lodwick, and Marco Breda. 2016. "The H Function: A New Index for Detecting Structural/Topological Complexity Information in Undirected Graphs." Physica A 447: 355-378.

Buscema, Paolo M., Marco Breda, and Luigi Catzola. 2009. "The Topological Weighted Centroid, and the Semantic of the Physical Space-Theory." In Artificial Adaptive Systems in Medicine, edited by Paolo M. Buscema and Enzo Grossi, 68-78. London: Bentham.

Buscema, Paolo M., Marco Breda, Enzo Grossi, Luigi Catzola, and Pierluigi Sacco. 2013. "Semantics of Point Spaces through the Topological Weighted Centroid and Other Mathematical Quantities: Theory and Applications." In Data Mining Applications Using Artificial Adaptive Systems, edited by William J. Tastle, $75^{-139}$. New YorkLondon: Springer.

Buscema, Paolo M., Enzo Grossi, and Tom Jefferson. 2009. "The Topological Weighted Centroid, and the Semantic of the Physical Space - Application." In Artificial Adaptive Systems in Medicine, edited by Paolo M. Buscema and Enzo Grossi, 79-89. London: Bentham.

Buscema, Paolo M., Riccardo Petritoli, Giovanni Pieri, and Pierluigi Sacco. 2009. AutoContractive Maps. Semeion - Technical Paper 32. Roma: Aracne.

Buscema, Paolo M., and Pierluigi Sacco. 2010. "Auto-Contractive Maps, the H Function, and the Maximally Regular Graph (MRG): A New Methodology for Data Mining." In Applications of Mathematics in Models, Artificial Neural Networks and Arts, edited by Vittorio Capecchi, 227-276. New York-London: Springer.

Buscema, Paolo M., and Pierluigi Sacco. 2016. "Mst Fitness Index and Implicit Data Narratives: A Comparative Test on Alternative Unsupervised Algorithms.” Physica A 461: 726-746.

Buscema, Paolo M., Pierluigi Sacco, Guido Ferilli, Marco Breda, and Enzo Grossi. 2015. "Analyzing the Semantics of Point Spaces Through the Topological Weighted Centroid 
and Other Mathematical Quantities: The Hidden Geometry of the Global Economic Order." Computational Intelligence 31 (3): 532-567.

Buscema, Paolo M., Pierluigi Sacco, Enzo Grossi, and Weldon A. Lodwick. 2013. "Spatiotemporal Mining: A Systematic Approach to Discrete Diffusion Models for Time and Space Extrapolation." In Data Mining Applications Using ArtificialAdaptive Systems, edited by William J. Tastle, 231-275. New York-London: Springer.

Childe, Vere Gordon. 1950. "The Urban Revolution." Town Planning Review 21: 3-17.

Clarke, David L. 1968. Analytical Archaeology. London: Methuen and Co.

Clarke, David L. 1972. Models in Archaeology. London: Methuen.

Clarke, David L. 1977. Spatial Archaeology. Boston: Academic Press.

Collar, Anna, Fiona Coward, Tom Brughmans, and Barbara J. Mills. 2015. "Networks in Archaeology: Phenomena, Abstraction, Representation." JAMT 22: 1-32.

Cooper, Jerrold. 1985. "Medium and Message: Inscribed Clay Cones and Vessels from Presargonic Sumer." RA 79: 97-114.

Figge, Udo L. 1991. "Computersemiotik." Zsem 13 (3-4): 321-330.

Finkbeiner, Üwe. 1986. "Uruk-Warka: Evidence of the Ğamdat Nasr-Period." In Ğamdet Nasr. Period or Regional Style? Papers Given at a Symposium Held in Tübingen, November 1983, edited by Üwe Finkbeiner and Wolfgang Röllig, 33-56. Beihefte zum Tübingen Atlas der Vorderen Orients, Reihe B 62. Wiesbaden: Reichert.

Gibson, McGuire. 1973. "Population Shift and the Rise of Mesopotamian Civilization." In The Explanation of Culture Change: Models in Prehistory, edited by Colin Renfrew, 447-463. Pittsburgh: University of Pittsburgh Press.

Hage, Per, Frank Harary, and James Brent. 1996. "The Minimum Spanning Tree Problem in Archaeology." AmAnt 61: 149-155.

Kendall, David G. 1971. "Seriation from Abundance Matrices." In Mathematics in the Archaeological and Historical Sciences, edited by Frank R. Hodson, David G. Kendall, and Petre Tăutu, 215-252. Edinburgh: Edinburgh University Press.

Knappett, Carl. 2011. An Archaeology of Interaction: Network Perspectives on Material Culture and Society. Oxford: Oxford University Press.

Kohler, Timothy. 2012. "Complex Systems and Archaeology." In Archaeological Theory Today, edited by Ian Hodder, 93-123. Cambridge: Polity Press.

Kohonen, Teuvo. 1982. "Self-Organized Formation of Topologically Correct Feature Maps." Biological Cybernetics 43: 59-69.

Kohonen, Teuvo. 1996. "Emergence of Invariant-Feature Detectors in the AdaptiveSubspace Self-Organizing Map." Biological Cybernetics 75: 281-291.

Kruskal, Joseph B. 1956. "On the Shortest Spanning Subtree of a Graph and the Traveling Salesman Problem." Proceedings of the American Mathematical Society 7 (1): 48-50. Leeuw, Sander van der. 2013. "Archaeology, Networks, Information Processing, and beyond". In Network Analysis in Archaeology. New Approaches to Regional Interaction, edited by Karl Knappet, 335-349. Oxford: Oxford University Press. 
Liverani, Mario. 2013. Immaginare Babele. Due secoli di studi sulla città orientale antica. Rome-Bari: Laterza.

Ludovico, Alessandro di, and Marco Ramazzotti. 2008. "Reconstructing Lexicography in Glyptic Art: Structural Relations between the Akkadian age and the Ur III Period." In Proceedings of the 51 st Rencontre Assyriologique Internationale, Held at the Oriental Institute of the University of Chicago, July 18-22 2005, edited by Robert D. Biggs, Jennie Myers, and Martha T. Roth, 263-280. SAOc 62. Chicago: The Oriental Institute of the University of Chicago.

Massini, Giulia. 2010. "Multi-Meta-Som." In Applications of Mathematics in Models, Artificial Neural Networks and Arts, edited by Vittorio Capecchi, 313-348. New YorkLondon: Springer.

McClelland, James L., and David E. Rumelhart. 1988. Explorations in Parallel Distributed Processing. Cambridge, MA: MIT Press.

Mézard, Marc, and Thierry Mora. 2009. "Constraint Satisfaction Problems and Neural Networks: A Statistical Physics Perspective." Journal of Physiology 103 (1-2): 107-113.

Miller, John H., and Scott E. Pages. 2007. Complex Adaptive Systems. An Introduction to Computational Models of Social Life. Princeton Studies in Complexity. Princeton: Princeton University Press.

Minsky, Marvin. 1986. The Society of Mind. New York: Simon \& Schuster.

Mlekuž, Dimitrij. 2014. "Exploring the Topography of Movement." In Computational Approaches to the Study of Movement in Archaeology, edited by Silvia Polla and Philip Verhagen, 5-22. Berlin: De Gruyter.

Nissen, Hans J. 1980. "The Mobility between Settled and Non-Settled in Early Babylonia: Theory and Evidence." In L'Archéologie de l'Iraq du début de l'époque néolithique à 333 avant notre ère, edited by Marie-Thérèse Barrelet, 285-290. Paris: Éditions du CNRs.

Nissen, Hans J. 1983a. "Settlement Patterns and Material Culture of the Akkadian Period: Continuity and Discontinuity." In Akkad, the First World Empire. Structure, Ideology, Traditions, edited by Mario Liverani, 91-106. Padova: Sargon.

Nissen, Hans J. 1983b. “The Urban Revolution of Mesopotamia Reconsidered.” In Studies in the Neolithic and Urban Revolutions. The V. Gordon Childe Colloquium, Mexico 1986, edited by Linda Manzanilla, 287-294. BAR-IS 349. Oxford: Archaeopress.

Nissen, Hans J. 2001. "Cultural and Political Networks in the Ancient Near East during the Fourth and Third Millennia BCE." In Mesopotamia and its Neighbors: Crosscultural Interactions and Their Consequences in the Era of State Formation, edited by Mitchell S. Rothman, 149-179. Santa Fe: SAR.

Porada, Edith, Donald P. Hansen, Sally Dunham, Sidney H. Babcock. 1992. "The Chronology of Mesopotamia, ca. 7000-1600 B.C." In Chronologies in Old World Archaeology, vol. 1., 3rd ed., edited by R.W. Enrich, 77-121. Chicago: University of Chicago Press.

Ramazzotti, Marco. 1997. "La fase 'Middle Uruk': studio tramite Reti Neurali Artificiali su un orizzonte latente nella protostoria della Bassa Mesopotamia." In Studi in me- 
moria di Henri Frankfort (1897-1954) presentati dalla scuola romana di Archeologia Orientale, edited by Paolo Matthiae, 495-522. CMAO VII. Roma: La Sapienza.

Ramazzotti, Marco. 1999. La Bassa Mesopotamia come laboratorio storico in età protostorica. Le Reti Neurali Artificiali come strumento di ausilio alle ricerche di archeologia territoriale. CMAO VIII. Roma: La Sapienza.

Ramazzotti, Marco. 2000. "Dall'analisi diacronica all'analisi sincronica: indagine sulle dinamiche insediamentali del periodo Jemdet Nasr nella regione di Warka." ScAnt $\mathrm{x}: 9-38$.

Ramazzotti, Marco. 2002. “La 'RivoluzioneUrbana' nella Mesopotamia meridionale. Replica 'versus' processo." Accademia Nazionale dei Lincei. Classe delle Scienze Morali Storiche e Filologiche, Rendiconti IX 13: 651-752.

Ramazzotti, Marco. 2003. "Modelli insediamentali alle soglie del Protodinastico in Mesopotamia meridionale, centrale e nord-orientale. Appunti per una critica alla formazione 'secondaria' degli stati nel III Millennio a.C." CMAO IX: 15-71.

Ramazzotti, Marco. 2009. "Lineamenti di archeologia del paesaggio mesopotamico. Descrizioni statistiche e simulazioni artificiali adattive per un'analisi critica della demografia sumerica e accadica." In Geografia del popolamento, edited by Giancarlo Macchi Jánica, 193-202. Siena: Fieravecchia.

Ramazzotti, Marco. 2010. Archeologia e Semiotica. Linguaggi, codici, logiche e modelli. Turin: Bollati Boringhieri.

Ramazzotti, Marco. 2013a. "Where Were the Early Syrian Kings of Ebla Buried? The UrEridu Survey Neural Model as an Artificial Adaptive System for the Probabilistic Localization of the Ebla Royal è madím." ScAnt XIX: 10-34.

Ramazzotti, Marco. 2013b. "Archeosema. Sistemi Artificiali Adattivi per un'Archeologia Analitica e Cognitiva dei Fenomeni Complessi." Acalc 24: 283-303.

Ramazzotti, Marco. 2013c. "Logic and Semantics of Computational Models for the Analysis of Complex Phenomena. Analytical Archaeology of Artificial Adaptive Systems." In Urban Coastal Area Conflicts Analysis Methodology: Human Mobility, Climate Change and Local Sustainable Development, edited by Armando Montanari, 23-56. Rome: La Sapienza.

Ramazzotti, Marco. 2013d. Mesopotamia antica. Archeologia del pensiero creatore di miti nel Paese di Sumer e di Accad. Rome: Editoriale Artemide.

Ramazzotti, Marco. 2014a. "Analytical Archaeology and Artificial Adaptive Systems." In Archeosema. Artificial Adaptive Systems for the Analysis of Complex Phenomena. Collected Papers in Honour of David Leonard Clarke, edited by Marco Ramazzotti, $15-52$. Acalc: Supplemento 6. Florence: All'Insegna del Giglio.

Ramazzotti, Marco. 2014b. "Analytical Archaeology and Artificial Adaptive Systems Laboratory (LAA\&AAs)." In Archeosema. Artificial Adaptive Systems for the Analysis of Complex Phenomena. Collected Papers in Honour of David Leonard Clarke, edited by Marco Ramazzotti, 53-84. Acalc: Supplemento 6. Florence: All'Insegna del Giglio. 
Ramazzotti, Marco. 2016a. "Archeologia e traduzione. Prolegomena alla meccanografia e alla simulazione artificiale del sema." In Il segno tradotto. Idee, immagini, parole in transito, edited by Marco Ramazzotti, Simone Celani, and Francesco Fava, 17-26. Milan: Marcos y Marcos.

Ramazzotti, Marco. 2016b. "Back to the Future. Structuring an Analytical Model for the Mesopotamian Urbanism: a View from the South." In Trajectories of Complexity. Socioeconomic Dynamics in Upper Mesopotamia in the Neolithic and Chalcolithic Periods, edited by Marco Iamoni and Salam al Quntar, 183-194. StTr 6. Wiesbaden: Harrassowitz.

Redman, Charles L. 1978a. The Rise of Civilization. From Early Farmers to Urban Society in the Ancient Near East. San Francisco: W. H. Freeman and Co.

Redman, Charles L. 1978b. "Mesopotamian Urban Ecology: The Systemic Context of the Emergence of Urbanism." In Social Archaeology. Beyond Subsistence and Dating, edited by Charles L. Redman, 329-348. New York: Academic Press.

Reeler, Claire. 1999. "Neural Networks and Fuzzy Logic Analysis in Archaeology." In Archaeology in the Age of the Internet. Proceedings of the 25th Anniversary Conference, University of Birmingham, April 1997, edited by Lucie Dingwall, Sally Exon, Vince Gaffney, Sue Laflin, and Martijn van Leusen, 3-10. BAR-IS 750. Oxford: Archaeopress. Rothman, Mitchel S. 1987. "Graph Theory and the Interpretation of Regional Survey Data." Paléorient 13 (2): 73-91.

Shuchat, Alan H. 1984. "Matrix and Network Models in Archaeology." Mathematics Magazine 57 (1): 3-14.

Smith, Michael E. 2011. "Empirical Urban Theory for Archaeologists." JAMT 18: 167-192. Smolensky, Paul. 1987. "Connectionsit AI, Symbolic AI, and the Brain." Artificial Intelligence Review 1: 95-109.

Stein, Gil. 2010. "Local Identities and Interaction Spheres: Modeling Regional Variation in the 'Ubaid Horizon." In Beyond the Ubaid: Transformation and Integration in the Late Prehistoric Societies of the Middle East, edited by Robert A. Carter and Graham Philip, 23-44. SAOC 63. Chicago: The Oriental Institute of the University of Chicago.

Weiss, Harvey. 1977. "Periodization, Population and Early State Formation in Khuzestan." In Mountains and Lowlands: Essays in the Archaeology of Greater Mesopotamia, edited by Louis Levine and Cuyler Young, 347-369. Malibu: Undena Publications.

Wright, Henry T. 1977. "Recent Research on the Origin of the State." ARA 6:379-397.

Wright, Henry T. 1978. "Toward an Explanation of the Origin of the State." In Origins of the State: The Anthropology of Political Evolution, edited by Ronald Cohen and Elman R. Service, 49-68. New York: Institute for the Study of Human Issues.

Wright, Henry T. 1981. "The Southern Margins of Sumer: Archaeological Survey of the Area of Eridu and Ur." In Heartland of Cities, edited by Robert McCormick Adams, 297-362. Chicago-London: University of Chicago Press. 
Wright, Henry T. 1984. "Prestate Political Formations." In On the Evolution of Complex Societies: Essays in Honor of Harry Hoijer, edited by William T. Sanders, Henry T. Wright, and Robert McCormick Adams, 41-78. Malibu: Undena.

Wright, Henry T. 1986. "The Susiana Hinterlands during the Era of Primary State Formation." In The Archaeology of Western Iran. Settlement and Society from Prehistory to the Islamic Conquest, edited by Frank Hole, 141-155. Washington, DC: Smithsonian Institution Press.

Wright, Henry T. 1998. "Uruk States in Southwestern Iran." In Archaic States, edited by Gary Feinman, and Joyce Marcus, 173-192. Santa Fe: SAR.

Wright, Henry T. 2001. "Cultural Action in the Uruk World". In Mesopotamia and its Neighbors: Cross-cultural Interactions and their Consequences in the Era of State Formation, edited by Mitchell S. Rothman, 123-148. Santa Fe: SAR.

Wright, Henry T., and Gregory A. Johnson. 1975. "Population, Exchange, and Early State Formation in Southwestern Iran." AmA 77: 267-289.

Young, Timothy C. 1972. "Population Densities and Early Mesopotamian Urbanism." In Man, Settlement and Urbanism, edited by Peter J. Ucko, Ruth Tringham, and Geoffrey W. Dimbleby, 827-842. London: Duckworth.

Zubrow, Ezra B. W. 2003. "The Archaeologist, the Neural Network, and the Random Pattern: Problems in Spatial and Cultural Cognition." In The Reconstruction of Archaeological Landscapes through Digital Technologies. Italy-United States Workshop, Boston, Massachusetts, USA, November, 1-3, 2001, edited by Maurizio Forte and Patrick R. Williams, 173-180. British Archaeological Reports 1151. Oxford: Oxbow. 
PART 2

Objects 